\title{
Elemente und Ephemeride des Planeten (120).
}

Aus den Beobachtungen Marseille April 10 und April 17, Paris-Hamburg April 30 und Hamburg Mai 11 habe ich folgende Elemente und Ephemeride des Planeten (120) berechnet:

Mittl. Aequin. 1872,0.

Epoche: Mai 12,5 mittl. Berl. Zt.

$$
\begin{aligned}
& M_{a}=321^{\circ} 33^{\prime} 37^{\prime \prime} 5 \\
& \pi=24336 \quad 0.0 \\
& \Omega=3415037.8 \\
& i=64638.4 \\
& \varphi=7556.5 \\
& \log a=0,009238 \\
& \mu=611^{\prime \prime} 153
\end{aligned}
$$

\begin{tabular}{|c|c|c|c|c|}
\hline \multicolumn{2}{|c|}{$12^{\text {h }}$ Berl. Zt } & $\alpha$ & $\delta$ & $\log \Delta$ \\
\hline Mai & 20 & $11^{\mathrm{h}} 48^{\mathrm{m}} 27^{\mathrm{s}}$ & $-4^{0} 7^{\prime} 5$ & 0.3633 \\
\hline & 21 & 35 & 8.3 & \\
\hline & 22 & 44 & 9.3 & \\
\hline & 23 & 54 & 10.4 & \\
\hline & 24 & 496 & 11.6 & 0.3715 \\
\hline & 25 & 18 & 13.0 & \\
\hline & 26 & 114932 & $-4 \quad 14.4$ & \\
\hline
\end{tabular}

\begin{tabular}{|c|c|c|c|c|c|}
\hline i $2^{\mathrm{h}} \mathrm{B}$ & erl. Zt. & $\alpha$ & & $\delta$ & $\log \Delta$ \\
\hline Mai & 27 & $11^{h} 49^{n}$ & ${ }^{n} 47^{8}$ & $-4^{0} 16^{\prime} 0$ & \\
\hline & 28 & 50 & 4 & 17.7 & 0.3798 \\
\hline & 29 & & 21 & 19.5 & \\
\hline & 30 & & 40 & 21.5 & \\
\hline & 31 & 51 & 0 & 23.5 & \\
\hline Juni & 1 & & 21 & 25.7 & 0.3882 \\
\hline & 2 & & 43 & 28.0 & \\
\hline & 3 & 52 & 7 & 30.3 & \\
\hline & 4 & & 31 & 32.8 & \\
\hline & 5 & & 57 & 35.5 & 0.3966 \\
\hline & 6 & 53 & 24 & 38.2 & \\
\hline & 7 & & 52 & 41.0 & \\
\hline & 8 & 54 & 21 & 44.0 & \\
\hline & 9 & & 51 & 47.1 & 0.4049 \\
\hline & 10 & $5 \overline{5}$ & 22 & 50.2 & \\
\hline & 11 & & 55 & 53.5 & \\
\hline & 12 & 56 & 28 & $-4 \quad 56.9$ & \\
\hline & 13 & 1157 & 2 & $\begin{array}{ll}-5 & 0.4\end{array}$ & 0.4133 \\
\hline
\end{tabular}

Die Correction meiner Ephemeride des PI. (119) war am 16. Mai: $+6^{8}$ in $A R,-0^{\prime} 6$ in Decl.

Hamburg, 1872 Mai $17 . \quad$ C. F. Pechüle.

\section{Entdeckung eines neuen Planeten (121).}

I have observed a new planet discovered by me as follows:

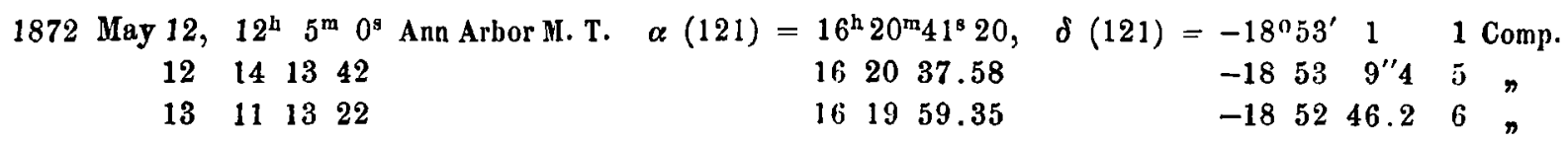

Daily motion: $\Delta \alpha=-43^{8}, \Delta \delta=+0^{\prime} 26^{\prime \prime}$. - The planet is 11 th magnitude.

Ann Arbor, 1872 May 14.

James C. Watson.

Correction der Ephemeride der Thetis (im Berliner Jahrbuch 1874).

1872 Juni $7+44^{8}$ in AR, $-0^{\prime} 2$ in Decl. Geschätzte Grösse: gut 10ter.

Bilk-Düsseldorf, Juni 1872.

R. Luther.

\section{Beobachtungen des Planeten (121).}

Herr Dr. Börgen hat den neuen Watson schen Planeten (121) folgendermaassen beobachtet:

$$
\begin{aligned}
& 1872 \text { Juni } 812^{\mathrm{h}} 48^{\mathrm{m}} 4^{\mathrm{s}} \text { mittl. Leipz. Zt. } \alpha \text { app. }=16^{\mathrm{h}} 0^{\mathrm{m}} 28^{\mathrm{s}} 98, \quad \delta \text { app. }=-18^{\circ} 40^{\prime} 13^{\prime \prime} 1 \\
& 11113448 \quad \pi \quad \pi \quad 155824.71 \quad \pi \quad-183921.5
\end{aligned}
$$

Die Beobachtung Juni 8 wurde durch Wolken erhalten.

Leipzig, 1872 Juni 12.

C. Bruhns. 